\title{
Application of Matrix Converter in Wind Energy Conventional System Employing PMSG
}

\author{
N.Venkatesh ${ }^{1}$, G.Pandu ranga reddy ${ }^{2}$ \\ ${ }^{1}$ (Electrical \& Electronics, G.P.R.E.C, A.P, India) \\ ${ }^{2}$ (Electrical \& Electronics, G.P.R.E.C, A.P, India
}

\begin{abstract}
Over the last ten years, the global wind energy capacity has increased rapidly and became the fastest developing renewable energy technology. The controllability of the wind turbines becomes more and more important as the power level of the turbines increases. Nowadays, for generating units above $1 M W$, variable speed concepts are usually applied that are either based on doubly fed induction machines or converter-driven synchronous machines. Synchronous generator are widely used in standalone WECS, Though the requirements are not fulfilled directly by the machine, the control strategy is used in both the stator as well as rotor side along with power electronic converters to fulfill the requirements stated above. In this paper, matrix converter has to be introduced for wind power applications. Major technical features and advantages are going to describe.
\end{abstract}

Keywords - Matrix Converter, Pmsg, WECS

\section{INTRODUCTION}

The last few years has seen a huge Investment in renewable energy resources as alternative sources of energy. Wind energy is the fastest growing source of renewable energy in the power industry and it will continue to grow worldwide as many countries are formulating plans for its future development. Many countries have developed plans to meet the growing energy demands in the future by taking advantage of the abundant energy in wind so as to protect the environment from $\mathrm{CO} 2$ released through some of the more conventional ways of generating power.

The U.S. is targeting about $20 \%$ of the electricity produced in 2030 to be from wind energy. For power system operators, increasing contribution of wind energy to the grid poses new challenges that need to be addressed in order to ensure the reliability and the security of the electric power grid [1]. Many technologies have competed over the years for the concept of designing the generators and the power electronics used for the control of wind turbines. Wind turbines have evolved from using fixed speed turbines to using variable speed turbines that improves the controllability of the energy tapped from the wind. Modern wind turbines allow a variable speed operation of the generator through a power converter interface with the grid.

Now a days, for generating units above $1 \mathrm{MW}$, variable speed concepts are usually applied that are either based on doubly fed induction machines or converter-driven synchronous machines. Some of the largest units currently available and therefore especially suited for off-shore applications are built on the direct drive synchronous machine concept [3].

This paper presents a direct AC-AC matrix converter, as an alternative to the DC-link voltage-sourced converter. In this paper, first, a brief description of WECS is provided. Then, it is demonstrated how the wind energy can be optimally captured and converted to electric energy using a wind turbine, a permanent magnet synchronous generator and a matrix converter. Finally, the simulation results based on the proposed WECS are presented to support the theoretical expectations.

\section{1 overview}

\section{DIRECT DRIVE SYNCHRONOUS GENERATORS}

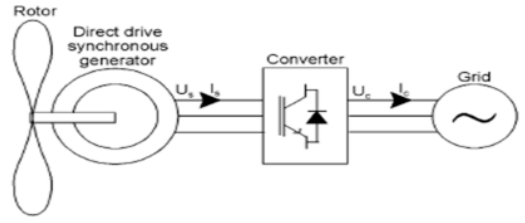

fig 1: direct drive synchronous generator 
Figure 1 shows the principal arrangement of a direct drive synchronous generator. Rotor and generator shafts are mounted to the same shaft without gear-box. The generator is a high-pole synchronous generator

designed for low speed [3]. Considering the energy yield and reliability, the direct-drive generator systems seem to be more powerful compared to geared drive systems, especially for offshore. The direct-drive permanent magnet synchronous generator system (PMSG DD) is more superior compared to other systems in terms of losses and energy yield [4]. For allowing variable speed operation, the synchronous generator must be connected to the grid through a frequency converter. One of possibility for the frequency converters are matrix converters.

The matrix converter (MC) provides direct $\mathrm{AC}-\mathrm{AC}$ conversion and is considered an emerging alternative to the conventional two-stage AC-DC-AC converter topology [5]. A matrix converter provides a large number of control levers that allows for independent control on the output voltage magnitude, frequency and phase angle, as well as the input power factor. When compared with the AC-DC-AC converter system, the bold feature of MC is elimination of the DC-link reactive elements, e.g. bulky capacitors and/ or inductors. However, this topology has not yet found its appropriate place in industrial applications. The main reasons behind this are the potential commutation problems, requiring complex control and buffer circuits, unavailability of monolithic bi-directional switches, lack of decoupling between the two ac sides of the converter, and low voltage gain.

\subsection{Wind Turbine}

\section{WIND ENERGY CONVERSION SYSTEM MODELLING}

The mechanical power that the turbine extracts from the wind $\mathrm{P}_{\mathrm{m}}$ is inferior to $\mathrm{P}_{\mathrm{w}}$. This is due to the fact that the wind speed after the turbine isn't zero. So, the power coefficient of the turbine $\mathrm{C}_{\mathrm{p}}$ can be defined by

$$
C_{p=\frac{P_{w}}{P_{m}}} \quad \text { Where } \mathrm{C}_{\mathrm{p}}<1
$$

The recuperated power is given by:

$$
P_{m}=\frac{1}{2} \rho C_{p} A_{r} V_{w}^{3}
$$

Where $A_{r}$ is wind turbine rotor swept area $\left(\mathrm{m}^{2}\right)$.

$$
\begin{aligned}
& \mathrm{V}_{\mathrm{w}}{ }^{3} \text { is wind speed }(\mathrm{m} / \mathrm{s}) \text {. } \\
& \mathrm{P} \text { is air density }\left(\mathrm{Kgm}^{3}\right)
\end{aligned}
$$

$\mathrm{C}_{\mathrm{p}}$ depends on tip speed ratio $\lambda$ and pitch angle $\beta$. Tip speed ratio is the ratio of blade tip speed to wind speed. $\beta$ is the pitch angle which is the angle between the plane of rotation and the blade cross-section chord.

$$
\lambda=\frac{\omega_{t}^{*} R}{v_{w}^{3}}
$$

$\mathrm{R}$ is radius of the turbine $(\mathrm{m})$, and $\mathrm{W}_{\mathrm{t}}$ is angular velocity of the rotor $(\mathrm{r} / \mathrm{sec})[6]$.

The power coefficient can be utilized in the form of look-up tables or in form of a function. The second approach is presented below, where the general function defining the power coefficient as a function of the tipspeed ratio and the blade pitch angle is defined as

$$
C_{p}(\lambda, \beta)=0.5\left(\frac{116}{\lambda_{i}}-0.4 \beta-5\right) e^{\frac{-16.5}{\lambda_{i}}}
$$

Where $\lambda_{\mathrm{i}}$ is

$$
\lambda_{i}=\frac{1}{\frac{1}{\lambda+0.089 \beta}-\frac{0.035}{\beta^{3}+1}}
$$

The rate of the rotor speed is proportional to the inverse of the inertia and difference between wind turbine mechanical torque $(\mathrm{Tm})$ and the generator electrical torque $(\mathrm{Te})$. The wind turbine output mechanical torque is affected by $\mathrm{Cp}$. In order to maximize the aerodynamic efficiency, the torque Te of the synchronous generator is controlled to match with the wind turbine torque $\mathrm{Tm}$ to have maximum possible $\mathrm{Cp}$ max. With a power converter, adjusting the electrical power from the synchronous generator controls the Te; therefore, the rotor speed can be controlled. For the system to operate at maximum power at all wind speeds, the electrical output power from the power converter controller must be continuously changed so that under varying wind speed condition the system is matched always on the maximum power locus[3].

The model of the wind turbine implemented in Simulink is shown in Fig. 2. 


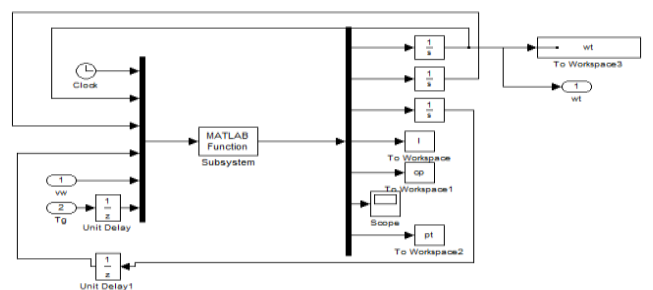

Fig. 2. Simulink model of turbine

\subsection{Permanent magnet synchronous generator}

The PMSG has been considered as a system which makes possible to produce electricity from the mechanical energy obtained from the wind. Permanent Magnet Generator provides an optimal solution for varying-speed wind turbines. This eliminates the need for separate base frames, gearboxes, couplings, shaft lines, and pre-assembly of the nacelle. The output of the generator can be fed to the power grid directly. High level of overall efficiency can be achieved.

The dynamic model of the PMSG is derived from the two phase synchronous reference frame, which the q-axis is $90^{\circ}$ ahead of the $\mathrm{d}$-axis with respect to the direction of rotation. Fig. 3 shows the $d$ - $q$ reference frame used in a salient-pole synchronous machine (which is the same reference as the one used in a PMSG), where $\theta$ is the mechanical angle, which is the angle between the rotor d-axis and the stator axis [7].

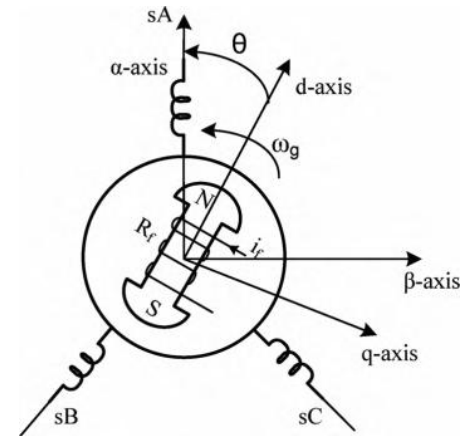

Fig. 3. $-d-q$ and $\alpha-\beta$ of a typical salient-pole synchronous machine.

The stator windings are positioned sinusoidal along the air-gap as far as the mutual effect with the rotor is concerned; the stator slots cause no appreciable variations of the rotor inductances with rotor position; magnetic hysteresis and saturation effects are negligible; the stator winding is symmetrical; damping windings are not considered; the capacitance of all the windings can be neglected and the resistances are constant (this means that power losses are considered constant).

The stator windings are positioned sinusoidal along the air-gap as far as the mutual effect with the rotor is concerned; the stator slots cause no appreciable variations of the rotor inductances with rotor position; magnetic hysteresis and saturation effects are negligible; the stator winding is symmetrical; damping windings are not considered; the capacitance of all the windings can be neglected and the resistances are constant (this means that power losses are considered constant).

The mathematical model of the PMSG in the synchronous reference frame is given by the following equations[7].

$$
\begin{aligned}
& \frac{d \boldsymbol{i}_{d}}{d t}=\frac{1}{L_{l s}+L_{m d}}\left(-R_{s} i_{d}-\omega_{e}\left(L_{l s}+L_{m q}\right) i_{q}+V_{d}\right) \\
& \frac{d \boldsymbol{i}_{q}}{d t}=\frac{1}{L_{l s}+L_{m q}}\left(-R_{s} i_{q}-\omega_{e}\left[\left(L_{l s}+L_{m d}\right) i_{d}+\varphi_{f}\right]+V_{q}\right)
\end{aligned}
$$


Where

$i d, i q: \mathrm{d}-\mathrm{q}$ axis stator currents,

$R s$, : stator resistance,

Lmd , $L m q$ : d-q axis inductance,

Lls: stator inductance,

$\psi f$ : magnet flux.

$\mathrm{W}_{\mathrm{e}}$ is angular velocity of the generator defined by

$$
\omega_{e}=p \omega_{t}
$$

Where $\mathrm{p}$ is the number of pole pairs The electromagnetic torque may be expressed in terms of the stator currents and stator flux linkages as

$$
T_{e}=\left(\frac{1}{2}\right)\left(\frac{P}{2}\right)\left(\left(L_{m d}-L_{l s}\right) i_{q} i_{d}+\varphi_{f}\right)
$$

Main technical problems connected with distributed generation system operation are voltage and power stability. This group of problems is often solved with simulators based on dq transformation. However, these simulators do not comprehend solution of harmonics, which can be present during transient and specific cases could cause errors in protection functions. Fig. 4. shows the equivalent circuit of the PMSG in de $d$ - $q$ synchronous rotating reference frame.

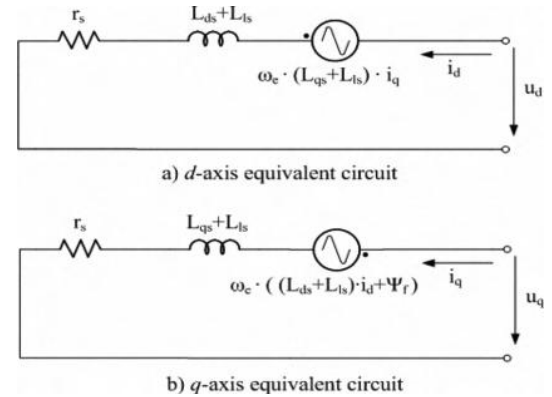

Fig. 4.Equivalent circuit of the PMSG in the synchronous frame.

Figure 5. shows the simulink model of the permanent magnet synchronous generator.

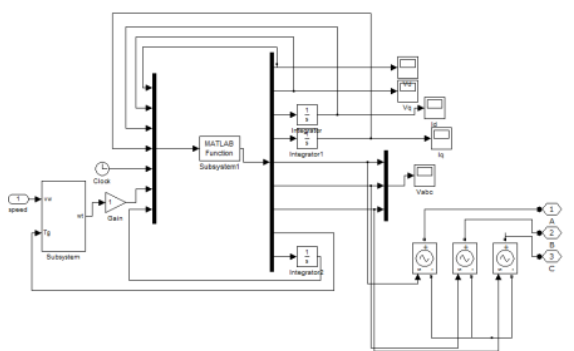

Fig.5. simulink model of permanent magnet synchronous generator

\subsection{Matrix Converter}

The matrix converter is a forced commutated converter which uses an array of controlled bidirectional switches as the main power elements to create a variable output voltage system with unrestricted frequency. It does not have any dc-link circuit and does not need any large energy storage elements [5].

\subsubsection{Conventional Matrix Converter Topology}

The conventional matrix converter topology is composed of an array of nine bi-directional switches connecting each phase of the input to each phase of the output. By properly operating the switches in the matrix converter, one can achieve control on the output voltage magnitude, frequency and phase angle, as well as control on the input displacement angle. Matrix converter is a bi-directional power flow device with the capability of producing high quality input and output waveforms [8]. Figure 6 shows the schematic diagram of a conventional matrix converter. 


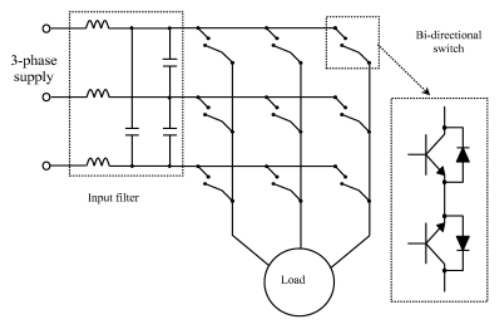

Fig. 6.Schematic Diagram of a Conventional Matrix Converter

A serious drawback attributed to the conventional matrix converter topology is the commutation problems associated with the operation of the four-quadrant switches. Safe operation of the switches requires complicated switching strategies imparting the elegance of the topology.

\subsubsection{Improved matrix converter topology}

Figure 7 shows the schematic diagram of the improved matrix converter topology. The improved matrix converter is based on the concept of "fictitious dc link" used in controlling the conventional matrix converter. However, there is no energy storage element between the line-side and load-side converters.



Fig.7. schematic diagram of the improved matrix converter

The improved matrix converter topology has the following advantages with respect to the conventional matrix converter topology:

1. The commutation problems associated with the switches have been solved.

2. All the switches at the line-side turn on and turn off at zero current.

As shown in Figure 7, matrix converter offers four control levels that can be used to control the input displacement angle and output voltage magnitude, frequency and phase angle. The model discussed above has been implemented in Matlab / Simulink environment and this shows the converter and the inverter portion in Matrix Converter. The simulated model is shown in Figure 8. The output of the synchronous generator is given to the input of the matrix converter.

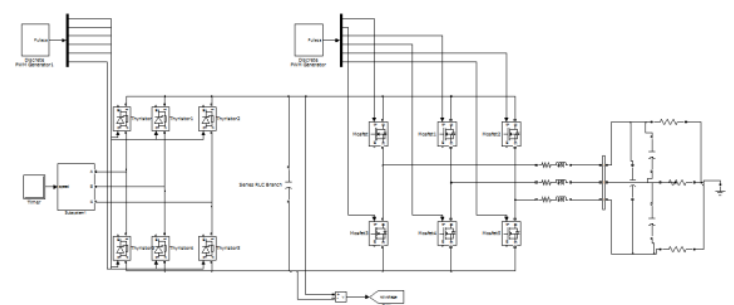

Fig.8. simulink model of improved matrix converter

\section{Simulation ReSUlts AND ANALYSiS}

The system level simulation is made utilizing Matlab/Simulink. This software represents all the switches as ideal switches. The turbine characteristics and synchronous generator output voltage waveforms are obtained to test the feasibility of proposed control method. In this section, the simulation results obtained from system is presented. 


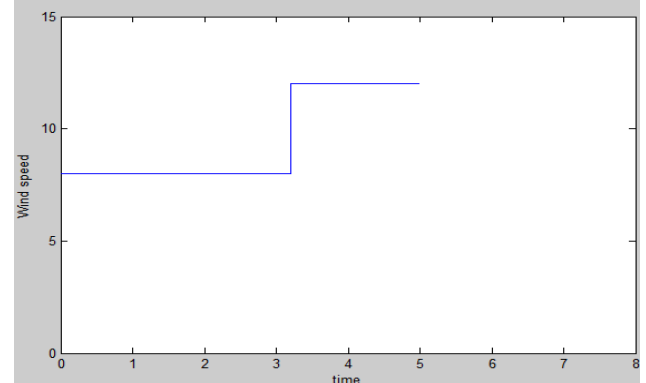

Fig.9. wind velocity $(\mathrm{m} / \mathrm{s})$ vs time(s)

In order to assess the capability of the system at varying wind velocity, a step change in the wind velocity is applied to the system. The system is first operating at the wind velocity of $8 \mathrm{~m} / \mathrm{s}$. At $\mathrm{t}=3.2 \mathrm{secs}$, the wind velocity is increased to $12 \mathrm{~m} / \mathrm{s}$. This shown in Figure 9.

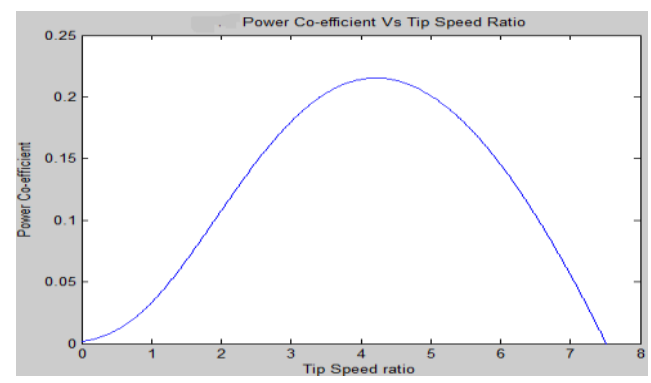

Fig.10. power coefficient vs tip speed ratio

Cp- $\lambda$ Curve can be used in wind turbine design to determine the rotor power for any combination of wind velocity and rotor speed. They provide immediate information on the maximum rotor power co-efficient and optimum tip speed ratio. Figure 10 shows the maximum value of $\mathrm{Cp}$ is 0.22 , which is achieved at tip speed ratio of 4 . The maximum efficiency is observed for the maximum value of $\mathrm{Cp}$.

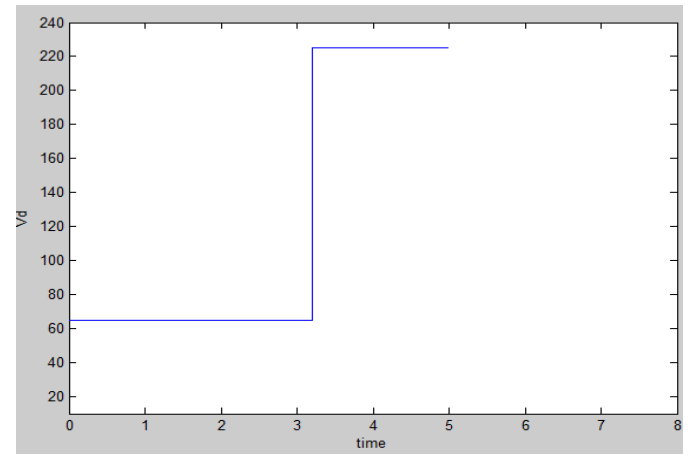

Fig.11. d axis voltage(v) vs time(sec)

The Figure 11 shows the variation in synchronous generator direct axis output voltage with the change in wind velocities. As the wind velocity increases, the generator output voltage also increases. For the wind velocity of 8 $\mathrm{m} / \mathrm{s}$ the generator produces the output voltage of 65 Volts and for $12 \mathrm{~m} / \mathrm{s}$ the output voltage reaches to 225 Volts. Further increase in wind speed increases the generated voltage. 


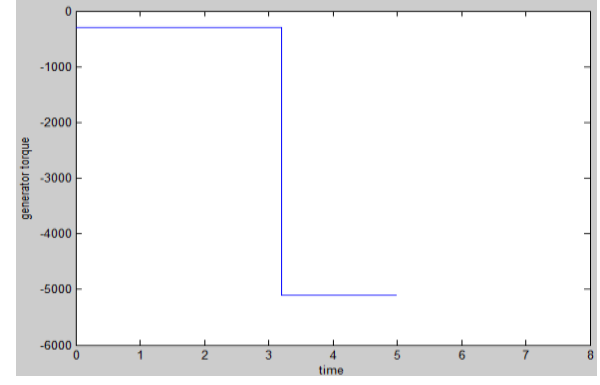

Fig. 12. Generator torque (Nm) vs time (sec)

When the synchronous machine operates as a generator, the torque produced is negative indicating that the machine is in braking mode as the operating frequency is less than the supply frequency or regeneration mode when the operating frequency is higher than the supply frequency for variable speed drives applications. Figure 12 shows the variation of generated torque with timeIt can be observed from the graph that the Torque and the Speed settles down after certain instant while simulation, this shows that the Mathematical Model is perfectly working for the parameters provided to it and also the Model generated has been executed as expected.

The generator output voltage given to the input voltage to the matrix converter.

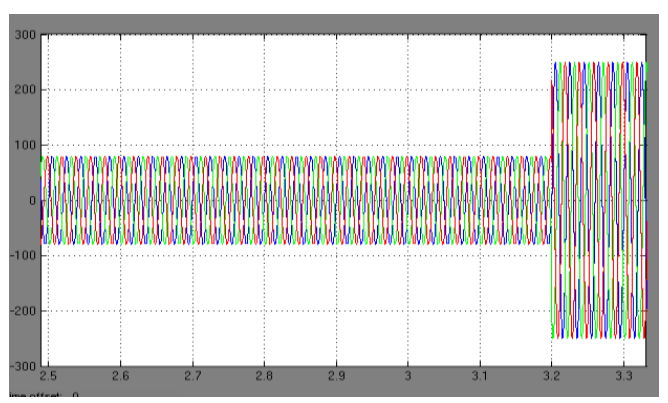

Fig.13. matrix converter input voltage(vol) vs time(s)

The figure 13 shows the input voltage to the matrix converter from the synchronous generator with the variation of the step change in the wind velocity.

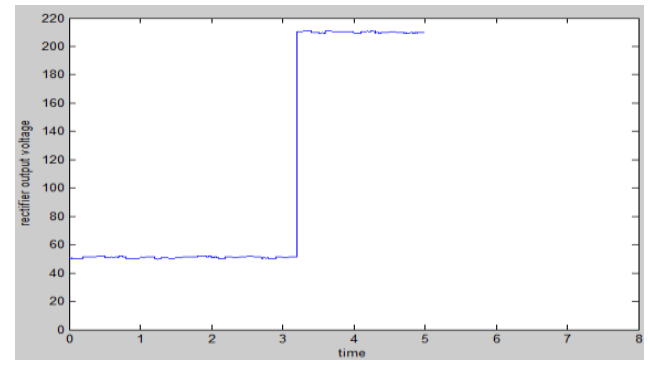

Fig. 14. Rectifier output voltage(vol) vs time(s)

The input voltage of the matrix converter is given to fully controlled converter. The rectified output voltage of the matrix converter for the wind velocity of $8 \mathrm{~m} / \mathrm{s}$ is 55 Volts and for $12 \mathrm{~m} / \mathrm{s}$ is 210 Volts. 


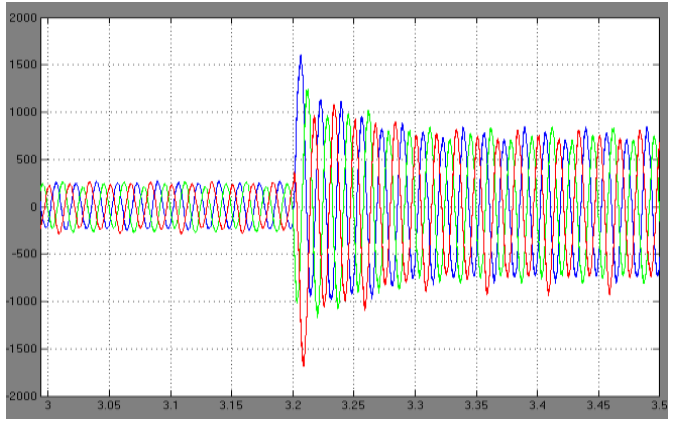

Fig. 15. Matrix output voltage vs time

Figure 15 shows the variations in the matrix converter output voltage that results in necessary changes in the synchronous generator terminal frequency and voltage.

\section{Conclusion}

The wind turbine driven synchronous generator is modeled using Matlab/Simulink tool and is also analyzed for various wind velocities. As the speed increases, both frequency and amplitude of the output voltage from the permanent magnet synchronous generator also increases. In order to obtain the constant output voltage with constant frequency, the synchronous generator is coupled with the matrix converter. A controlled rectifier rectifies the output voltage of permanent magnet synchronous generator and rectified output is given to the inverter. As there is no DC link element between the converter and the inverter, the converter produces the constant DC voltage irrespective of wind velocities. The constant DC voltage from the converter is given to the input of inverter to obtain an AC output voltage of constant amplitude with constant frequency. There by constant output voltage with constant frequency is obtained from the proposed Wind Energy Conversion Scheme. Simulation results show successful generation of power and output voltage from the wind at various wind velocities.

\section{APPENDIX}

Wind turbine parameters are

Air density $(\rho)=1.225 \mathrm{Kg} / \mathrm{m}^{3}$

Blade radius $=29.2 \mathrm{~m}$

Pitch angle $=19^{\circ}$

Generator parameters are

Rated generated power $(\mathrm{P})=250 \mathrm{Kw}$

No. Of poles $=4$

Stator resistance $\left(\mathrm{R}_{\mathrm{s}}\right)=0.14 \Omega$

Stator inductance $\left(\mathrm{L}_{\mathrm{is}}\right)=0.9 \mathrm{mH}$

D-axis inductance $\left(\mathrm{L}_{\mathrm{md}}\right)=43 \mathrm{mH}$

Q-axis inductance $\left(\mathrm{L}_{\mathrm{mq}}\right)=20 \mathrm{mH}$

\section{References}

[1] "Behavior of double fed induction generator under near by wind fault plant" by Olumide Aluko, Student Member, IEEE, Travis M. Smith, Senior Member, IEEE, Leon M. Tolbert, Senior Member, IEEE.

[2] “Application of A Matrix Converter for PMSGWind Turbine Generation System" by Guoliang Yang, and Yanping Zhu

[3] "Application of matrix converter in wind energy conventional sources by employing synchronous generator" by J. Karpagam*, P.S. Mayurappriyan*, Jovitha Jerome. $\dagger$

[4] "Review of generator systems for direct drive wind turbines" by D. Bang, H. Polinder, G. Shrestha, J.A. Ferreira.

[5] P.W.Wheeler, J. Rodriguez, J. Clare,L. Empringham, and A.Weinstein, "Matrix Converters: A Technology Review" IEEE Trans. on Industrial Electronics vol.:49, No:2, 2002 pp 276-289.Trans. on Industrial Electronics vol.:49, No:2, 2002, pp 276-289.

[6] "Modeling And Control of A Wind Turbine Using Permanent Magnet Synchronous Generator" by S.Vijayalakshmi, Asst.Prof.EEE, SRM University, Saikumar.S, Saravanan.S,R.V.Sandip, Vijay Sridhary.

[7] "Modeling of a Variable Speed Wind Turbine with a Permanent Magnet Synchronous Generator" by Alejandro Rolan', Alvaro Luna, Gerardo Vazquez, Daniel Aguilar Gustavo Azevedo.

[8] L. Wei, T.A. Lipo, “A Novel Matrix Converter Topology with simple Commutation”, IEEE Press , pp 1749-1754. 